\title{
EVASÃO NO ENSINO SUPERIOR: UM ESTUDO DE CASO NA EDUCAÇÃO A DISTÂNCIA - EAD
}

\author{
INDAIAL/SC MAIO/2018 \\ Sônia Adriana Weege \\ - UNIASSELVI - sonia.weege@uniasselvi.com.br \\ Daniele Cristine Maske \\ - UNIASSELVI - daniele.maske@uniasselvi.com.br \\ Tipo: Investigação Científica (IC) \\ Natureza: Relatório Final de Pesquisa \\ Categoria: Estratégias e Políticas \\ Setor Educacional: EDUCAÇÃO SUPERIOR
}

\begin{abstract}
RESUMO
A evasão é tema de estudo nos diversos segmentos da educação. Entendemos a evasão, como a desistência definitiva pelo acadêmico do curso em que se encontra regularmente matriculado, podendo acontecer em qualquer momento do seu processo de formação. No ensino superior, na modalidade de educação a distância (EAD), a questão igualmente merece atenção. Neste sentido, são consideradas as especificidades desta modalidade de ensino que está centrada na autonomia, organização, gestão do tempo e estabelecimento de prioridades pelo acadêmico no processo de ensino e aprendizagem. Esta pesquisa tem por objetivo conhecer as causas de evasão dos acadêmicos do Curso Superior de Tecnologia em Gestão Pública na IES "X". Foram objeto de análise os motivos expostos pelos acadêmicos em seu ambiente virtual de aprendizagem (AVA) no momento da solicitação de cancelamento de sua matrícula. Foram analisados os períodos de janeiro de 2015 a dezembro de 2016. O procedimento metodológico adotado está caracterizado como uma pesquisa aplicada, bibliográfica e exploratória, com abordagem qualiquanti. Os indicadores apresentados revelaram que $o$ instrumento disponível no AVA do acadêmico utilizado para o cancelamento de matrícula necessita de aprimoramento, eis que os maiores números apresentados como causas para cancelamento não foram indicados, seguidos de "motivos particulares, pessoais e familiares". A descrição destas motivações é inócua, não permite reconhecer efetivamente as causas da evasão do curso. Outrossim, fica evidente a necessidade de continuação desta pesquisa, permitindo que se reconheçam outros elementos que possibilitem que a IES estabeleça uma política que reduza seus indicadores de evasão. Conclui-se pela análise realizada, que, como em outros segmentos da educação e do ensino superior, no Curso Superior de Tecnologia em Gestão Pública, a evasão é uma realidade.
\end{abstract}

Palavras-chave: Evasão. Educação a Distância.Causas de evasão.

\section{AGRADECIMENTOS}

AGRADECEMOS A CONTRIBUIÇÃO DOS SETORES INTRAINSTITUCIUONAIS. 


\section{INTRODUÇÃO}

A educação a distância está sendo oportunizada e representa um processo de democratização e propagação do ensino para formação no ensino médio e no ensino superior, além de ser utilizada para a formação continuada e o aperfeiçoamento profissional. Sua regulamentação, da mesma forma que em outras áreas, é originária de leis, decretos, resoluções e portarias, editadas pelo Ministério da Educação e Cultura (MEC,2016).

Podemos observar que o ensino a distância apresenta um caráter inclusivo, pode ser disponibilizado em territórios distantes e distintos, estimula a autonomia do processo de ensino e aprendizagem, ou seja, leva a educação para locais em que a educação tradicional não pode ser ofertada e proporciona ao acadêmico escolhas para uma melhor apreensão do seu conteúdo de formação. Mesmo com todas estas possibilidades, a educação a distância eventualmente pode ser atingida pela evasão.

Ao que se sabe, o fenômeno da evasão ocorre por motivos diversos (LOBO, et al,2007), entre eles, a não adaptação ao modelo de ensino, problemas financeiros, projeto pedagógico do curso insipiente, e outros tantos que poderiam ser elencados. Em razão deste cenário, surge a motivação para esta pesquisa que é compreender quais as causas que levam o acadêmico a abandonar definitivamente seus estudos, mais especificamente aqueles que ingressaram no Curso Superior de Tecnologia em Gestão Pública na modalidade EAD na instituição "X" e evadiram no período de janeiro de 2015 a dezembro de 2016.

\section{FUNDAMENTAÇÃO TEÓRICA}

\subsection{Breves Considerações acerca da Educação a Distância}

A sociedade e a forma de interação dos diversos setores que a integram evoluíram. Nesta perspectiva, a educação igualmente trouxe contextos inovadores. Entre eles, um processo de ensino e aprendizagem que deixou de estar centrado em propostas tradicionais, sendo norteado por tecnologias e orientado para a autonomia do acadêmico. Dessa forma, nos deparamos com o surgimento da modalidade de ensino denominada de educação a distância, ou simplesmente EAD.

Segundo Guarezi e Matos (2009, p. 18), "são diversos os conceitos atribuídos à EAD, de caráter descritivo, com base no ensino convencional, destacando para diferenciá-las a distância (espaço) entre professor e aluno e o uso das mídias". Ao que se percebe, a 
percepção principal atribuída pelos autores para a educação a distância é a separação física entre o professor e o acadêmico, havendo a existência de tecnologias para mediar o processo de comunicação e de ensino e aprendizagem.

Pela inexistência da limitação de espaços físicos, a possibilidade de dispersão geográfica é evidente para a $E A D$, além da flexibilidade que esta detém, permitindo que o acadêmico tenha liberdade de escolha para acesso, horário, local etc., não sendo um modelo de ensino que possa ser classificado como rígido, entretanto, está vinculado a um projeto pedagógico. Além do já disposto, é igualmente clara a percepção de que a oferta da modalidade de ensino a distância pode ser realizada em larga escala.

A oferta do ensino na modalidade a distância, do mesmo modo que seu conceito, foi ampliada, adequando-se ao processo evolutivo da sociedade. Este desenvolvimento do processo de ensino e aprendizagem da EAD e a forma de fazê-lo ocorreu no mundo e no Brasil. A oferta inicialmente tímida, propagou-se, e, em razão desta ampliação no território brasileiro, o órgão regulamentador (MEC) editou normas específicas para que seja garantida a qualidade da educação àqueles que optarem por esta modalidade de ensino.

Independentemente deste desenvolvimento da EAD, sua disponibilidade, flexibilidade, aprimoramento dos materiais, qualificação dos atores envolvidos, da autonomia do acadêmico, regulamentação da qualidade, a evasão também é um elemento recorrente na EAD. Em razão desta assertiva, cabe o presente estudo, acerca das causas que levam à evasão do acadêmico na modalidade de ensino da educação a distância, como forma de compreensão e de possível intervenção nos aspectos relatados para o abandono definitivo de um processo de formação.

\subsection{Evasão: um fato na educação superior e na EAD}

A educação superior tem atividades complexas, relacionadas com valores éticos, epistêmicos, políticos, sociais, econômicos e culturais. Neste cenário de educação superior, a evasão é um fenômeno social complexo, podendo ser definida como uma interrupção no ciclo de estudos. A saída de acadêmicos provoca graves consequências sociais, acadêmicas e econômicas (BAGGI; LOPES, 2011), e, portanto, merece especial atenção das Instituições de Ensino Superior - IES - para a compreensão de suas causas ou motivações.

A evasão no ensino superior é um acontecimento que certamente atinge a todas as instituições de ensino no território brasileiro, sejam elas públicas ou privadas, não 
importando se a oferta de ensino é na modalidade presencial ou no ensino a distância. Segundo Lobo et al (2007, p. 641), "no setor público, são recursos públicos investidos sem o devido retorno. No setor privado, é uma importante perda de receitas. Em ambos os casos, a evasão é uma fonte de ociosidade de professores, funcionários, equipamentos e espaço físico". Acadêmicos que iniciam e não concluem, ou seja, abandonam definitivamente o ensino superior, são um desafio para as instituições de ensino.

Na educação a distância, o elemento "evasão" também é uma realidade vigente, sendo desafiador sobrepor todas as nuances que envolvem o ato do cancelamento definitivo da matrícula do acadêmico do curso superior na modalidade de ensino a distância. Neste sentido, é importante reconhecer que "a manutenção de alunos é crucial para as instituições de ensino, pois os alunos são a razão de ser dessas instituições" (KOTLER; FOX, 1994 apud MARTINS, 2016). Manter alunos é ação tão importante para as IES quanto matriculá-los, estas são as razões de sua própria existência.

É importante que a IES perceba que o processo de evasão pode ser considerado ameaçador, eis que, a percepção de manter o acadêmico é tão importante quanto sua captação. Como qualquer outro segmento econômico da sociedade, a oferta de serviços educacionais é um ambiente extremamente competitivo, e a concorrência é fator preponderante. Manter o acadêmico vinculado ao curso e à IES passa a ser fator diferencial neste mercado em expansão, com ofertas diversificadas que oportunizem ao acadêmico uma escolha pela instituição de ensino que seja mais adequada ao atendimento de suas expectativas e necessidades.

Entre os objetivos traçados pelas instituições de ensino superior privadas, temos o alcance de rentabilidade e de excelentes resultados financeiros, uma das possibilidades de atingir essas metas é pela retenção dos acadêmicos. Conhecer as causas que levam o acadêmico a evadir-se do curso ou da instituição, torna-se elemento essencial. O ensino superior como negócio e seu mercado têm suas próprias especificidades. A manutenção do vínculo do acadêmico com a instituição gera uma receita previsível levada em consideração para os custos operacionais.

A evasão de cada acadêmico representa uma perda de receita irrecuperável. A institucionalização de políticas de retenção do acadêmico pela IES e a análise de causas de evasão podem representar a manutenção da estabilidade da receita ou eventual lucratividade. O que vemos atualmente, é o foco das instituições de ensino na captação de acadêmicos, sendo que, aparentemente, a evasão é tratada como algo aceitável ou até esperado. A IES privada depende de forma quase exclusiva da renda 
advinda das mensalidades dos acadêmicos. Neste contexto, a compreensão do fenômeno da evasão em cada uma das IES pode ser fator primordial para a própria sobrevivência destas.

\section{PROCEDIMENTOS METODOLÓGICOS}

O procedimento metodológico adotado neste estudo está caracterizado como uma pesquisa aplicada, bibliográfica e descritiva, com abordagem qualiquanti. A natureza da pesquisa é aplicada, pois tem, nas palavras de Michel (2009, p. 44), "[...] como objetivo a aplicação, a utilização de conhecimentos e resultados adquiridos na pesquisa básica, estando voltada para o aspecto utilitário da pesquisa". Distingue-se como bibliográfica, pois inicialmente foram pesquisados os temas educação a distância e evasão em periódicos, publicações e livros da área. Qualifica-se em exploratória, pois "[...] tem como objetivo proporcionar um conhecimento sobre determinado problema ou fenômeno" (CASARIN; CASARIN, 2012, p. 41).

É também identificada como uma pesquisa qualiquanti, pois buscará reconhecer os motivos que levam o acadêmico da educação a distância a abandonar definitivamente o ensino superior e quantificar estas causas por relevância. O universo abrangido pelo estudo é dos acadêmicos do Curso Superior de Tecnologia em Gestão Pública (CST), modalidade de ensino EAD da Instituição de Ensino Superior (IES) "X", que cancelaram sua matrícula no período de janeiro de 2015 a dezembro de 2016. Esta amostra se apresentou suficiente para aferição da causa de evasão dos acadêmicos deste curso superior em EAD.

A coleta de dados foi realizada por meio da emissão de relatório originado da plataforma da modalidade EAD adotada pela IES para gestão e para o processo de ensinoaprendizagem dos cursos ofertados. A observação foi baseada na identificação das causas relacionadas pelos acadêmicos como propulsoras do seu pedido de cancelamento de matrícula. Neste caso, "a pesquisa quantitativa atua como organizadora de informações para serem analisadas crítica e qualitativamente" (MICHEL, 2009, p. 38). A partir da identificação quantitativa por ordem de relevância, as motivações para o cancelamento de matrículas foram mensuradas qualitativamente.

\section{ANÁLISE E APRESENTAÇÃO DOS RESULTADOS}

A evasão em todo o processo educativo é um elemento complexo, não o seria diferente na educação superior, principalmente nas instituições de ensino privadas. Com produto e serviço com claras especificidades e como proposição de atuação social em uma 
comunidade, a IES precisa reconhecer em seu âmbito de atuação as causas que levam o acadêmico a desistir definitivamente de seu curso. Conhecer as motivações, oportunizará à IES ações de melhorias e de regressão de eventuais taxas de evasão que possam comprometer, inclusive, sua saúde financeira.

A instituição de ensino superior pode mensurar a evasão de diversas formas, por curso, em períodos da oferta do curso etc. Um controle simples nos setores que registram as informações acadêmicas de forma organizada e metódica pode reportar esta informação. O importante para tal ação é que as informações estejam disponíveis de alguma forma, e de maneira clara e distinta, para que seja possível a identificação de fatores diversos ou até aleatórios que possam significar causas de evasão.

Passamos, então, à análise dos indicadores encontrados no CST GPU. Apresentaremos gráficos e as percepções apreendidas acerca dos indicadores, buscando compreender os fenômenos reconhecidos no processo de evasão deste curso do ensino superior na modalidade a distância a partir do Gráfico 1.

GRÁFICO 1 - CANCELAMENTO DE MATRÍCULAS POR SEMESTRE - IES "X" JANEIRO DE 2015 A DEZEMBRO DE 2016.

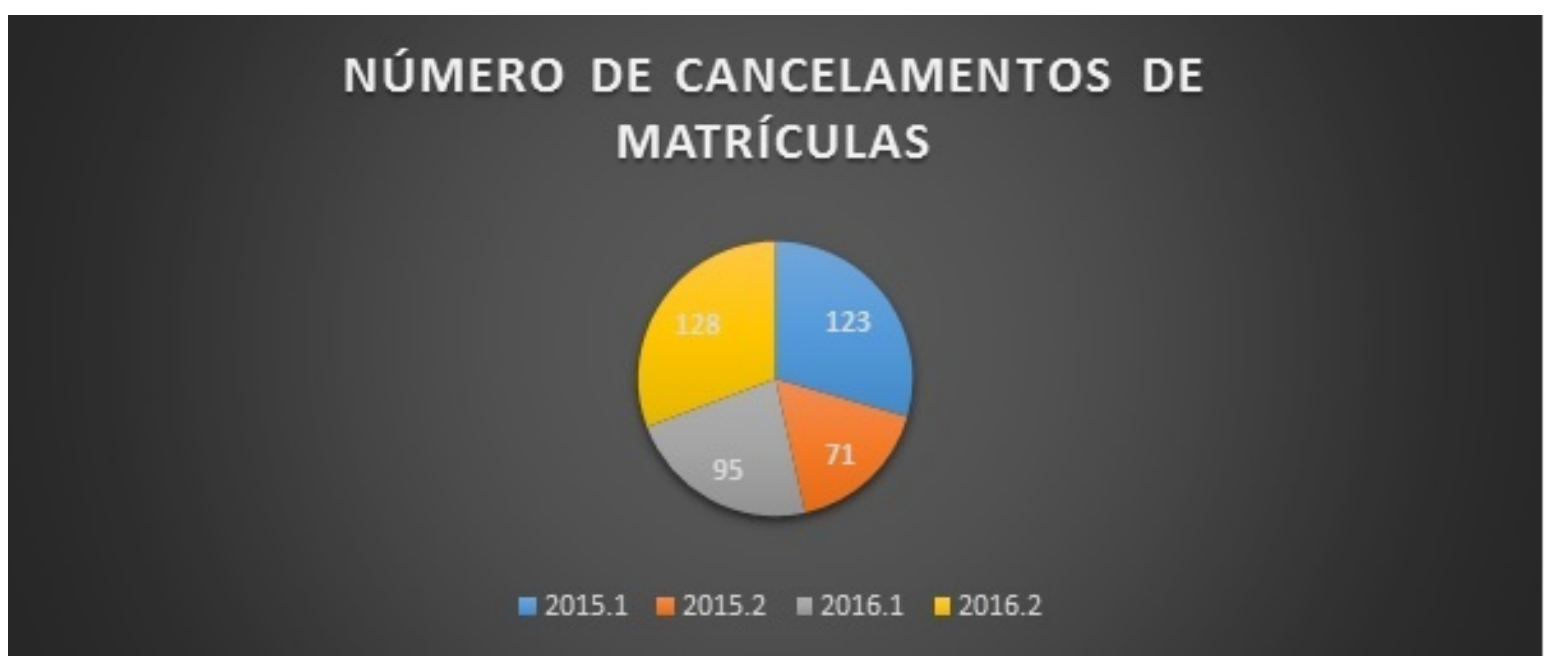

Fonte: Dados institucionais.

$\mathrm{Na}$ observação do Gráfico 1 acima, é perceptível um quantitativo maior de cancelamentos de matrículas nos semestres 2015.1 e 2016.2, e, por conseguinte, uma redução de evasão nos semestres 2016.1 e um quantitativo ainda menor em 2015.2. Já na tabela 1 abaixo apresentamos o quantitativo e as causas apresentadas pelos acadêmicos para sua desistência na graduação. 
TABELA 1 - SOMATÓRIA DAS CAUSAS INDICADAS NOS PEDIDOS DE CANCELAMENTOS DE MATRÍCULAS DOS ACADÊMICOS DO CURSO SUPERIOR DE TECNOLOGIA EM GESTÃO PÚBLICA - IES "X" - JANEIRO DE 2015 A DEZEMBRO DE 2016.

\begin{tabular}{|l|r|}
\hline CAUSAS & \multicolumn{1}{|c|}{ QUANTIDADES } \\
\hline Sem indicação de motivos & 136 \\
\hline Pessoal/particular/familiar & 68 \\
\hline Financeiro & 48 \\
\hline Incompatibilidade de horário & 38 \\
\hline Doença/saúde & 25 \\
\hline Winback & 22 \\
\hline Mudança de cidade & 12 \\
\hline Não abriu turma & 12 \\
\hline Mudança de curso & 10 \\
\hline Não frequentou o semestre & 10 \\
\hline Viagem & 9 \\
\hline Mudança de IES & 9 \\
\hline Não se adaptou ao modelo pedagógico & 3 \\
\hline Insatisfação com a IES & 2 \\
\hline Sem tempo para os estudos & 2 \\
\hline Desemprego & 2 \\
\hline Convocado para o exército & 2 \\
\hline Não gostou do curso & 2 \\
\hline Motivos Diversos & 5 \\
\hline
\end{tabular}

Fonte: Dados institucionais.

Observando a Tabela 1 acima, é perceptível que os maiores quantitativos estão representados com a expressão "sem indicação de motivo" ou ainda "motivos pessoais, particulares, familiares". Estas causas representam 48,9\% do número total de causas de cancelamento de matrículas. Entretanto, estas causas não permitem uma ação efetiva da IES para evitar que a evasão ocorra, já que a indicação destas causas é inócua, pois não permite a identificação clara dos motivos que levaram os acadêmicos a solicitarem o cancelamento de suas matrículas e evadirem do CTS GPU na modalidade EAD.

As causas financeiras estão classificadas na sequência, com um número significativo atribuído aos cancelamentos de matrícula, representando $11,5 \%$ do número total. Em seguida, temos a incompatibilidade de horário e as situações de doença/saúde. Faz-se necessário relembrar que o cancelamento de matrículas pode ser solicitado pelo próprio acadêmico e ser realizado pelos profissionais nos polos de apoio presencial, não sendo obrigatório o preenchimento do motivo para dar andamento ao processo de 
cancelamento de matrículas.

Analisando o gráfico 2 abaixo, em que a análise é percentual, comparando obviamente os acadêmicos regularmente matriculados em cada semestre e os que efetivamente cancelaram suas matrículas, temos uma evasão em 2015.1 de 17,98\%, em 2015.2 de 10,92\%, em 2016.1 de $16,58 \%$ e em 2016.2 de 18,65\%. Resta evidente que o menor percentual de evasão apresentado foi em 2015.2. Os percentuais apresentados são relevantes e significativos e devem ser analisados pormenorizadamente para que as causas para sua ocorrência possam ser minimizadas, eis que a sobrevida do curso está intimamente relacionada à retenção dos acadêmicos.

GRÁFICO 2 - ACADÊMICOS MATRICULADOS X CANCELAMENTO DE MATRÍCULAS - IES “X’ - JANEIRO DE 2015 A DEZEMBRO DE 2016.

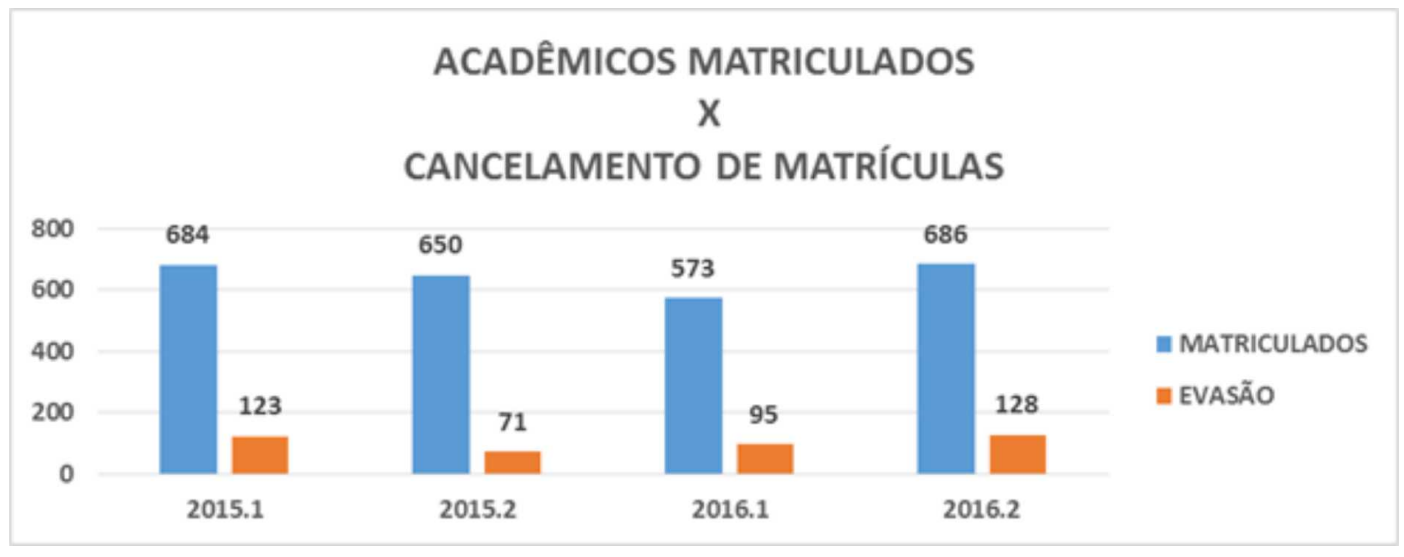

Fonte: Dados Institucionais.

Diante do exposto, foi possível observar que a evasão também é uma realidade no Curso Superior de Tecnologia em Gestão Pública na modalidade de educação a distância na IES "X”.

\section{CONSIDERAÇÕES FINAIS}

A realização de estudos acerca da evasão nas instituições de ensino superior é necessária para que se reconheçam suas causas e a IES efetivamente estruture políticas que evitem que seus acadêmicos desistam definitivamente de seus cursos. A análise das causas de evasão permite que se observem as eventuais fragilidades da instituição de ensino que podem ser superadas. A patir deste cenário uma política e ações de retenção de acadêmicos tem papel relevante.

Foi possível constatar que a forma e o processo de cancelamento de matrículas 
organizado na IES neste momento não é assertivo, não possibilita a identificação clara das causas que levam os acadêmicos à desistência do Curso Superior de Tecnologia em Gestão Pública na modalidade a distância. Neste contexto, cabe a sugestão de otimização da ferramenta utilizada para cancelamento de matrículas, inserindo para tanto, rol de causas, que levem o acadêmico a uma escolha ou indicação que motivou o cancelamento da matrícula.

Conclui-se que a evasão é uma realidade na IES e curso objetos da pesquisa e merece atenção. Uma política de retenção e controle de evasão que tenham como diretriz acompanhamento de presencialidade, acessos aos ambientes virtuais, reprovações, dentre outros podem resultar em decréscimo de abandono no ensino superior. Ignorar tais fatos, podem representar, no contexto macro, o comprmetimento da saúde financeira da IES. Diante deste cenário, sugere-se que a pesquisa seja ampliada para os demais cursos ofertados na modalidade a distância, da mesma forma que podem ser acrescidos os elementos observados, possibilitando uma melhor avaliação dos indicadores de evasão, contribuindo para a construção de uma política institucional de redução da evasão e retenção de acadêmicos interventiva e eficaz.

\section{REFERÊNCIAS}

BAGGI, Cristiane Aparecida dos Santos; LOPES, Doraci Alves. Evasão e avaliação institucional no ensino superior: uma discussão bibliográfica. Avaliação, vol. 16, n. 2, Campinas, 2011. Disponível em: . Acesso em: 27 dez. 2016.

BRASIL. Ministério da Educação. Resolução no 1, de 11 de março de 2016. Estabelece diretrizes e normas nacionais para a oferta de programas e cursos de educação superior na modalidade a distância. Disponível em: . Acesso em: 27 dez. 2016.

Ministério da Educação. Referenciais de qualidade para a EAD. 2007. Disponível em: . Acesso em: 27 dez. 2016.

Ministério da Educação. Comissão especial de estudos sobre evasão nas universidades públicas brasileiras. 1996. Disponível em: . Acesso em: 27 dez. 2016.

CASARIN, Helen de Castro Silva; CASARIN, Samuel Jose. Pesquisa cientifica da teoria à prática. Curitiba: Intersaberes, 2012. 
sem segredos. Curitiba: Editora IBPEX, 2009.

LOBO, Maria Beatriz de Carvalho Melo; et al. A evasão no ensino superior brasileiro. Cadernos de Pesquisa, v. 37, n. 132, p. 641-659, set. /dez. 2007

MARTINS, Cleidis Beatriz Nogueira. Evasão de alunos nos cursos de graduação em uma instituição de ensino superior. Disponível em: . Acesso em: 27 dez. 2016.

MICHEL, Maria Helena. Metodologia e pesquisa cientifica em ciências sociais. 2. ed. atualizada e ampliada. São Paulo: Atlas, 2009. 